\title{
Investigation of Disasters with Different InSAR Methods
}

\author{
Bekir Gündoğdu*1(i), Hediye Erdoğan 1(i), Osman Oktar $1(\mathbb{D}$ \\ ${ }^{1}$ Aksaray University, Faculty of Engineering, Department of Geomatics Engineering, Aksaray, Turkey
}

\author{
Keywords \\ Disaster \\ SAR \\ InSAR \\ DInSAR \\ PS-InSAR \\ Change Analysis
}

\begin{abstract}
Disasters can cause many loss of life and property every year. Although sudden disasters such as earthquakes and tsunamis cannot be detected in advance, knowing where and when disasters may occur or quickly determining the impact area of a disaster is the main factor in preventing these losses. For this reason, many different measurement methods have been developed by various professional disciplines in order to examine disasters. One of these methods is the Interferometric Synthetic Aperture Radar (InSAR) method, which is a remote sensing method. In this study, the 2015 Chile Illapel earthquake with the Differential SAR Interferometry (DInSAR) method based on the InSAR method, the vertical deformations and change analysis in the Konya Karapınar district, and the California Carr fire with the Permanent Scatterer SAR Interferometry (PS-InSAR) method were investigated. As a result of the investigations, the deformation in the LOS direction in the 2015 Chile Illapel earthquake region was found to be $\sim 151 \mathrm{~cm}$ and the vertical deformations in the Konya Karapınar district were found in the range of 6.4 to $-63.7 \mathrm{~cm}$. Additionally, the initial and full spread area of the California Carr fire were determined.
\end{abstract}

\section{INTRODUCTION}

People have struggled with various disasters throughout history. Disasters can be caused by natural causes such as earthquakes, tsunamis, landslides, or due to human-induced causes such as fire, plane crash and explosions (Altun, 2018). When examined in general, it is not known where and when disasters will occur, but disasters cause similar effects in terms of their results. These are social, economic and psychological effects, especially loss of life and property. However, these factors emerge over time and can not be used to quickly determine the impact areas of disasters. Many disasters physically affect the environment where they occur. Although these effects generally occur during or immediately after the disaster, some effects may also occur before the disaster. In this way, it is possible to examine disasters. In this direction, many different measurement methods have been developed by various professional disciplines (Tomás and Li, 2017). The most effective of these methods are the remote sensing methods, which have developed considerably in recent years. In this research, the InSAR method, which is a remote sensing method, was used.

'Radar' means range and target detection via radio waves. Radar systems have an active structure unlike optical remote sensing systems. Active systems generate their own energy. Thus, they determine the spatial and formal properties of objects on earth or in space by using the electromagnetic waves they produce. The reflection of radar signals takes place on a principle similar to that the sound wave reflects off an object and returns to the observer. The energy carried by the wave used is reflected back after reaching the object, the reflected energy is called 'echo' (Ballk, 2004). Thanks to the echo, an image expressed in pixel value is produced depending on the power of the returning electromagnetic wave (Akabalı, 2002). Thus, spatial and formal features of objects on earth or in space are determined.

The first InSAR study on disasters was carried out by Massonnet and Rabaute (1993) on the California-based Landers earthquake that took 
place on 28.06.1992. Massonnet and Rabaute Landers used two SAR images and an existing Digital Elevation Model (DEM) 65 days before (24.04.1992) and 355 days (18.06.1993) after the earthquake to study the earthquake. As a result of the study, they determined that the 7.3 magnitude Landers earthquake caused a $112 \mathrm{~mm}$ movement. After these studies, the InSAR method started to be used in disaster studies. Important information was obtained about the types, characteristics and locations of disasters by using this method. 1992 Landers (Peltzer et al., 1994; Price and Sandwell, 1998), 1993 Nevada Eureka Valley (Massonnet and Feigl, 1995; Peltzer and Rosen, 1995), California Northridge (Massonnet et al., 1996; Murakami et al., 1996), 1995 Japan Kobe (Ozawa et al., 1997) earthquakes; Etna Volcano (Massonnet et al., 1995), Pu'u O'o (Rosen et al., 1996), Hawaii; Vadon and Sigmundsson, 1997), Japan Izu Peninsula (Fujiwara et al., 1998) volcanic movements; , subsidences caused by coal mining (Carnec et al., 1996; Haynes et al., 1997), sunsidences in oil fields (Fielding et al., 1998) are the first examples of such studies analyzed with the InSAR method.

In this study, the 2015 Chile Illapel earthquake with the Differential SAR Interferometry (DInSAR) method based on the InSAR method, the vertical deformations and change analysis in the Konya Karapinar district with the Permanent Scatterer SAR Interferometry (PS-InSAR) method and the California Carr fire were investigated. To process the images, SARPROZ program developed by Prof. Dr. Daniele PERRISIN was used (Url-1).

\section{METHOD}

Since radar systems are active systems, the length of the radar antenna is directly related to the power of the transmitted wave and the capture of the reflected echo. The antenna lengths that radar systems can carry are limited. This limit is $1-2 \mathrm{~m}$ for airplanes and up to $10-15 \mathrm{~m}$ for satellites. These antenna sizes cannot physically provide sufficient resolution for distant targets. Therefore, the idea of creating a synthetic aperture was born to solve the size problems. According to this idea put forward by Carl Wiley (1951), platform motion and signal coherence are used to obtain a large antenna length. Thus, a very large antenna length would be synthesized by combining the phases of all reflections as the radar system moved between pulse transmissions. Radar systems whose antenna dimensions are synthesized in this way are called Synthetic Aperture Radar (SAR) (Elachi, 1988; Curlander and Donough, 1991). In this method, the synthetic aperture is generally created by sending a certain number of pulses in a certain time during the forward movement of the radar carried on an aircraft or a satellite (Ristau, 1999) (Figure 1).

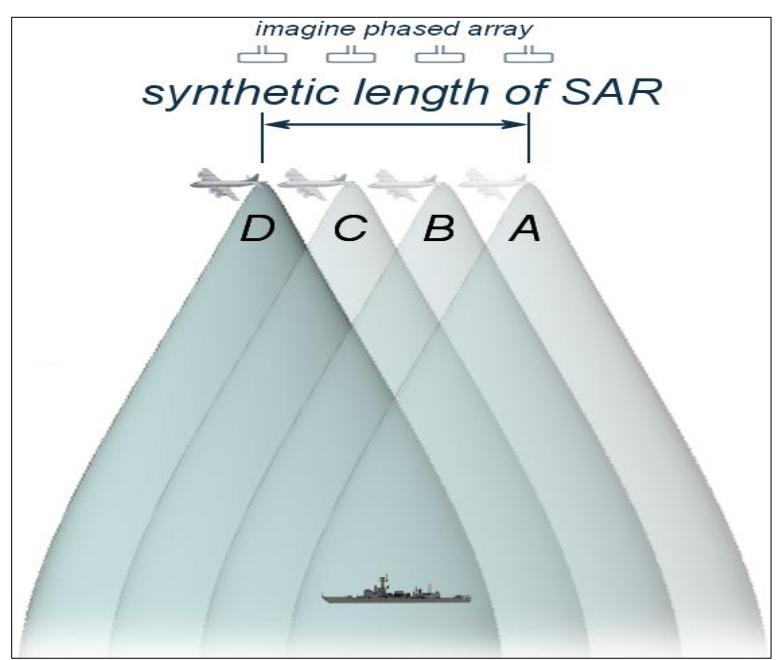

Figure 1. Working principle of synthetic aperture radars (Url-2)

Interferometry is a method of obtaining the height or height changes of a certain point by making use of the different phase and amplitude characteristics of two electromagnetic waves with the same frequency. SAR Interferometrisi ise tek bir nokta yerine birden fazla noktanın bulunduğu SAR görüntülerinin kullanıldığı bir interferometri yöntemidir. In the InSAR method, the difference of the phase values corresponding to the point is needed to determine the height of the points on the image in the Line of Sight (LOS) direction or their movement in the LOS direction. The phase information of the SAR images is used to obtain this difference. Therefore, if there are at least two SAR images of a particular area and some of the pixels can be precisely aligned, information about the relative phase, ie height, of each point in the image can be obtained (Goldstein and Zebker 1987; Gabriel et al., 1989; Goldstein et al., 1993; Massonnet et al., 1993). In the InSAR method, SAR images are separated and matched as master image or slave image. The amplitude values of the interferogram created after the images are matched are obtained by multiplying the amplitude values of the master image with the amplitude values of the slave image. Phase values are obtained by subtracting the phase values of the slave image from the phase values of the master image. The resulting image creates an interference pattern, just like contour lines maps. The values of the pixels that make up the image range from $-\pi$ to $\pi$ and each pattern transition in the image shows that there is a deformation equal to half the wavelength used in image acquisition (Figure 2) (Curlender and McDonough, 1991; Çakır, 2003; Akoğlu, 2008; Şengün, 2008; Yılmaztürk, 2015). 


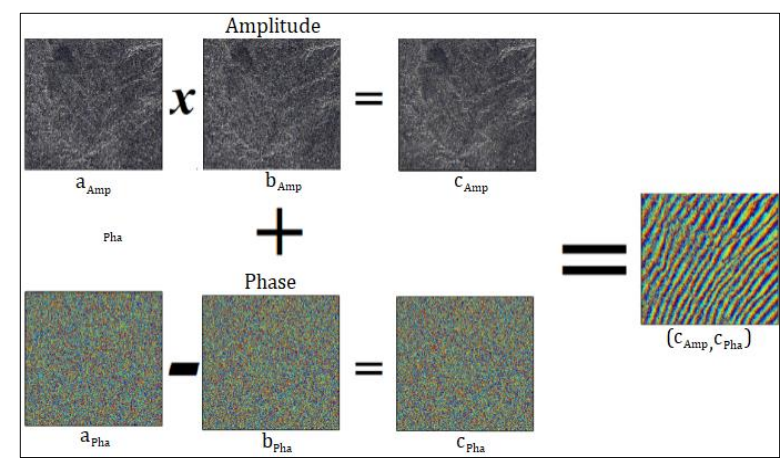

Figure 2. Interferogram formation from phase and amplitude values

DInSAR, PS-InSAR and change analysis methods used in the research are methods developed from the InSAR method. In order to use the InSAR method, at least one parameter of the SAR images that make up the interferogram must be different. This difference is called 'baseline'. (Bamler and Hartl, 1998). This difference is achieved by basically 3 different methods: single pass Along-Track method, single pass Across-Track and repeat pass method. However, although the methods differ depending on the way of image acquisition, the geometric principles of the methods are the same (Figure 3).

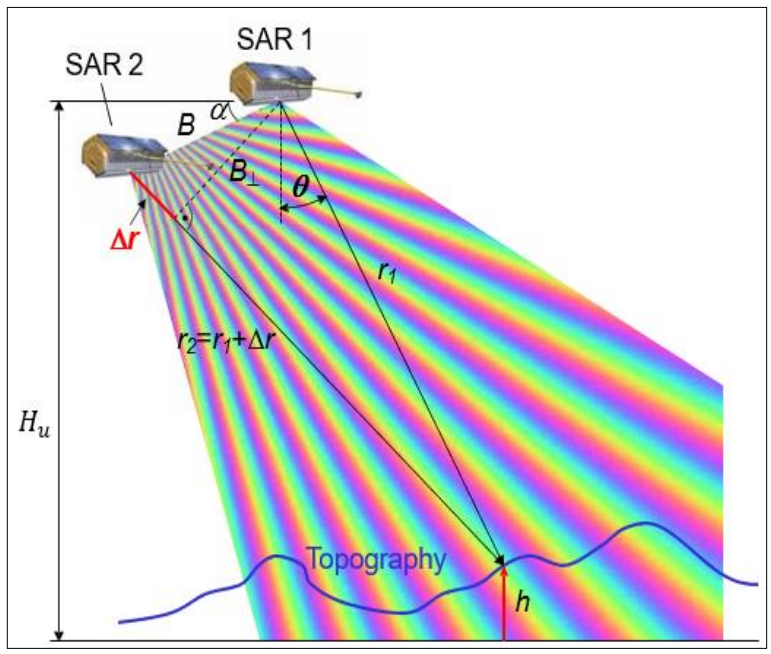

Figure 3. Interferometric SAR geometry

$B_{\perp}=B * \sin (\theta-\alpha)$

Here, the perpendicular basis is calculated by the equation in $B_{\perp} 1$, where $\alpha$ is the base slope, $\theta$ is the incidence angle, and $B$ is the spatial basis. In order to create interferograms, the perpendicular baseline must not exceed the maximum baseline (critical baseline) (Sandwell, 2002). Phase values of an InSAR image created with two SAR images whose perpendicular baseline does not exceed the critical baseline are obtained by transferring the phase differences of the corresponding pixels of the SAR images to the image (Hanssen, 2001).

$$
\begin{aligned}
& \phi_{1}=-\frac{4 \pi}{\lambda} r_{1} \\
& \phi_{2}=-\frac{4 \pi}{\lambda} r_{2}=-\frac{4 \pi}{\lambda}\left(r_{1}+\Delta_{r}\right)
\end{aligned}
$$

With Equation 2, the phase values in the first SAR image are calculated with the range of the first radar antenna $\left(r_{1}\right)$. With Equation 3, the phase values in the second SAR image are calculated with the range of the second radar antenna $\left(\mathrm{r}_{2}\right)$. Here, $\Delta_{\mathrm{r}}$ denotes the parallel base and is approximately equal to the difference between the two ranges.

$\Delta_{\phi}=\phi_{1}-\phi_{2}=\frac{4 \pi}{\lambda}\left(\Delta_{r}\right)$

The phase value of any pixel in the InSAR image is calculated by Equation 4 , where $\Delta \phi$ is the phase difference.

$h=H_{u}-r_{1} \cos \theta$

The height of the point from the ground (h) is calculated by Equation 5 .

$\cos \left(90^{\circ}-\alpha+\theta\right)=\frac{r_{1}^{2}+B^{2}-\left(r_{1}+\Delta_{r}\right)^{2}}{2 r_{1} B}$

$\theta=\alpha-90^{\circ}+\operatorname{acos}\left(\frac{r_{1}^{2}+B^{2}-\left(r_{1}+\Delta_{r}\right)^{2}}{2 r_{1} B}\right)$

The angle of incidence is calculated by the cosine law, where $\beta, \alpha$, and the distance of the radar antenna to the earth $\left(H_{u}\right)$ are known and $r_{1}$ and $r_{2}$ are measured values.

\subsection{DInSAR Method}

Theoretically, if there is no position difference between SAR images acquired at two different times, there is no vertical base and the phase of the interferogram depends only on the deformation between acquisition times. However, when the work is put into practice, it is seen that there is a position difference between the satellite images. The undesirable phase component from this difference also includes the topography component. For this reason, DInSAR method is used to eliminate the topography component in InSAR applications. In DInSAR method, DEM is used to simulate the topographic phase. First, the DEM is converted to radar coordinates and scaled using the base line. The topographic phase obtained from the scaled DEM is subtracted from the generated interferogram and the topographic phase is eliminated (Hansen, 2001). The geometry in which the DInSAR method is used is the same as in the classical InSAR geometry (Figure 4). 


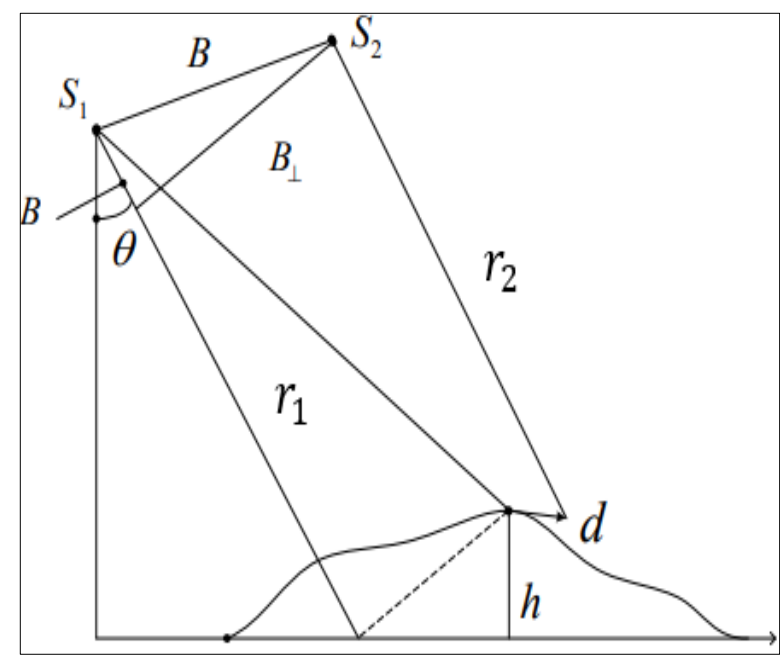

Figure 4. DInSAR geometry

Since satellites $S_{1}$ and $S_{2}$ observing the target point are in different positions, the phase component also includes the topography phase. However, since the desired phase is the differential phase, the topography phase must be eliminated.

$\varphi_{12}=-\frac{4 \pi}{\lambda}\left(R_{1}-R_{2}\right)=\varphi_{\text {diff }}+\varphi_{\text {top }}$

$\varphi_{\text {diff }}=\varphi_{12}-\varphi_{\text {top }}$
As seen in the equations 8 and $9, \varphi_{\text {diff }}$ is the differential phase and is obtained by subtracting the topography phase $\varphi_{\text {top }}$ from the created interferogram.

\subsection{PS-InSAR Method}

The PS-InSAR technique first emerged when the Polytechnic University of Milan (POLIMI) (1999) produced and patented the PS-InSAR algorithm. In the PS-InSAR technique, it is aimed to monitor radar targets that exhibit high phase stability during the observation period. While these targets are usually objects such as buildings, metallic objects, masts, antennas found in urban areas, they can also be fixed objects such as manmade objects and rocks found in non-urban areas. The use of SAR images in the PS-InSAR method is different from the DInSAR method. As in the DInSAR method, instead of a single interferogram created from two SAR images, analysis is made over time series created with multiple interferograms (Ferretti et al., 2000). The PS-InSAR method can also be defined as the statistical analysis of the amplitudes and phases of a series of SAR images collected at different times from different angles (Figure 5).

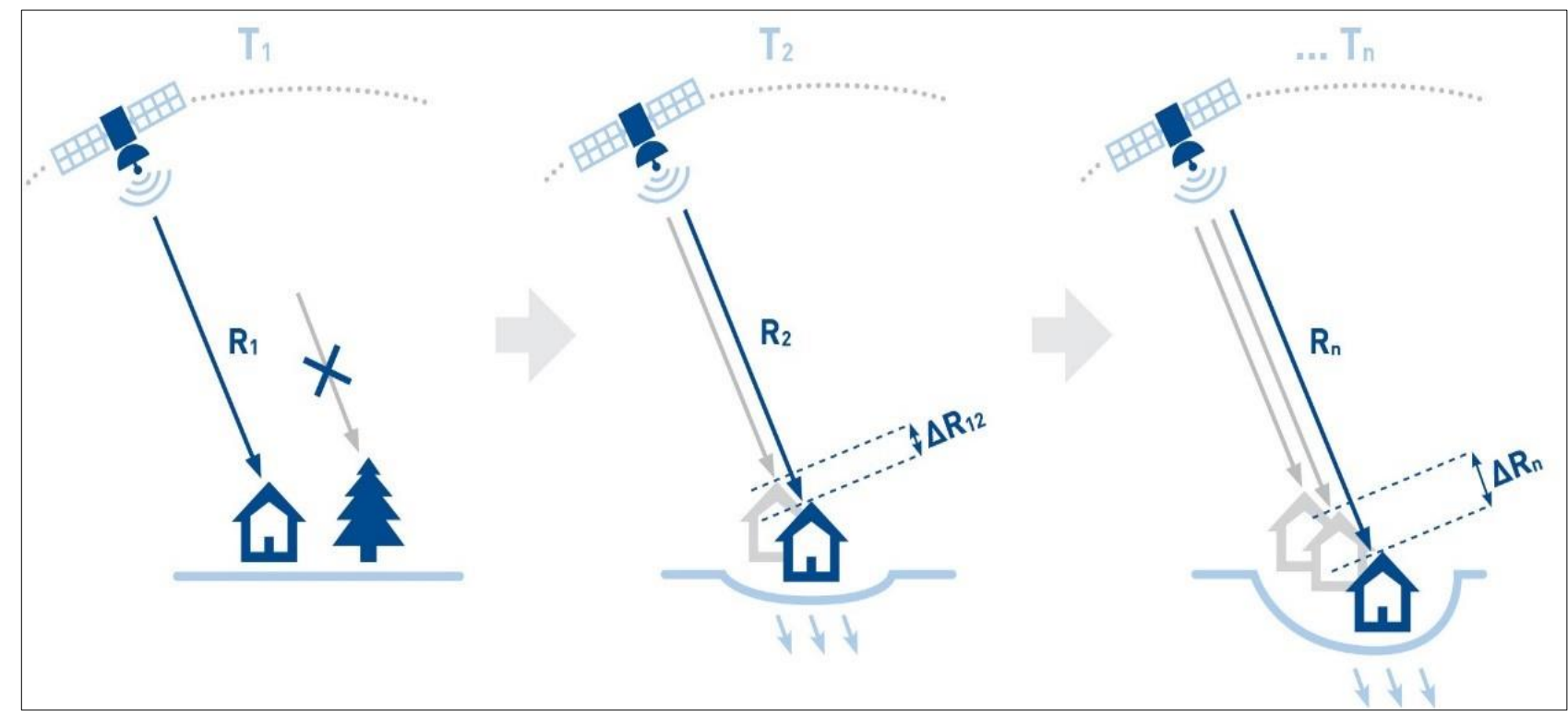

Figure 5. PS-InSAR geometry

When SAR images are acquired, the atmospheric phase has an effect that distorts the spatial correlation. However, the atmospheric phase is random and unrelated to time. The topographic phase is fixed and does not change with time. The motion-dependent phase term of the target, on the other hand, is usually time-related and may exhibit varying degrees of spatial correlation (e.g. subsidences coused from water pumping, fault displacements, locally floating areas, collapsed buildings). For this reason, phase components coming from the atmosphere and topography can be separated according to the PS positions and the phase resulting from the movement can be left alone (Rocca et al., 2010). In the PS-InSAR method, the deformation component includes linear or nonlinear phase components (Equation 10). Together with these components, the atmospheric phase component, the topographic component and the noise, the equation of a PS point is as follows (Wang et al., 2018): 


$$
\begin{gathered}
\Delta \varphi_{\text {diff }}=\frac{4 \pi}{\lambda} \Delta t \Delta v+\frac{4 \pi}{\lambda} * \frac{B_{\perp}}{\rho \sin \theta} \Delta h+\Delta \varphi_{\text {atms }}+ \\
\frac{4 \pi}{\lambda} \Delta D_{\text {non-lineer }}+\Delta \varphi_{\text {noise }}
\end{gathered}
$$

Given in Equation10, $\Delta t$ is the temporal basis, $\rho$ is the slope interval, $\Delta \varphi_{\text {diff }}$ is the differential observation. The nonlinear deformation rate $\Delta v$ and the residual topographic phase $\Delta h$ are unknowns. In addition, if the real differential phase is greater than $2 \pi$, the phase uncertainties should also be taken into account.

$\Delta \varphi_{x-y, i f g}^{k}=\left[a^{k}, b^{k}\right] *\left[\begin{array}{c}\Delta v_{x-y} \\ \Delta \mathrm{h}_{x-y}\end{array}\right]+\varepsilon(k=1,2 ., M)$

Equation 11, differential observations between $\mathrm{x}$ and $\mathrm{y}$ to neighboring PS points can be expressed assuming the number of images $\mathrm{M}$ in a series of interferograms. The $\Delta \varphi^{k} k_{x, y, f g}$ component is the coefficients of the differential phase generated between $\mathrm{x}$ and $\mathrm{y}, a^{k}$ and $b^{k}$ are mean velocity parameters and $\Delta h_{x-y}$ is the residual topographic phase. Here, $\Delta v_{x-y}$ and $\Delta h_{x-y}$ are unknowns and must be determined using the periodogram spectral analysis method using temporal consistency maximized. $\Delta v_{x-y}$ and $\Delta h_{x-y}$ are converted into a frequency domain in space by periodogram spectral analysis, and analysis is made by locating single PS points with the help of temporal coherence. The remaining phase residues are due to atmospheric influences and are used to estimate the atmospheric phase scan (APS) of each interferogram. That is, the atmospheric component is estimated together with the mean velocity $\Delta v_{x-y}$ and the residual topographic phase $\Delta h_{x-y}$. Atmospheric components in the differential phases can be removed by low-pass filtering in the spatial domain and by high-pass filtering in the temporal domain (Wang et al., 2018). Then, based on the PSC mesh, the positions and deformations of each point on the mesh are estimated starting from a reference point.

\subsection{Change Detecting}

Many different methods are used to determine the changes in the earth. Each method uses different parameters to determine the changes. Detection of changes with SAR images is usually done with the help of a pair of SAR images taken at different times in the same area. Since SAR data includes amplitude and phase information, it can be used as an indicator of change in both parameters. In the analysis of variation with amplitude values in SAR images, inconsistencies are determined by using the back-reflection properties of the signals. In the coherence mapping method, the coherence of the SAR image pair is used to determine the changes in the amplitude and phase of the pixels. Since the phases are sensitive to changes in the loop, the sensitivity of this method depends on the wavelength of the system used.

\section{STUDY AREA AND MATERIALS}

\subsection{Chile Illapel Earthquake}

Chile is a South American country occupying a long and narrow strip of land between the Andes and the Pacific Ocean. It is also part of the Pacific Ring of Fire. The Pacific Ring of Fire is highly mobile due to the collision between the Nazo and South American plates, which are highly seismic and volcanic. For this reason, earthquakes occur frequently in the region. In this study, the Chile Illapel earthquake, which took place in 2015, was investigated by DInSAR method. The 8.3 magnitude earthquake occurred off the ocean, $46 \mathrm{~km}$ west of Illapel. The earthquake that started at around 19.54 hours on 16.09.2015 lasted between 3 and 5 minutes. Immediately after the earthquake, three aftershocks with a magnitude of 7, 6.5 and 6.7, respectively, occurred (Figure 6).

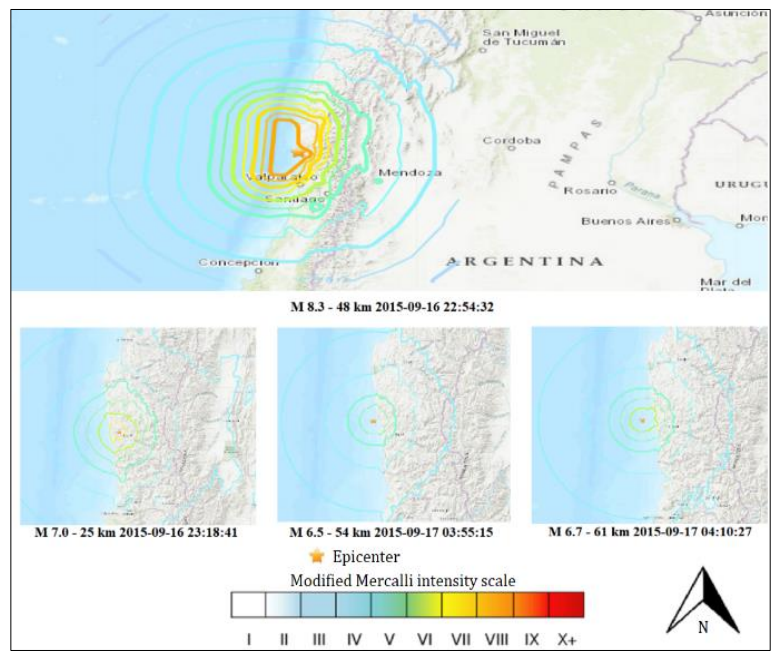

Figure 6. Impact map of the 2015 Chile Illapel and aftershocks

The impact of the earthquake covers a very large area of 93000 square kilometers. For this reason, 6 SAR images obtained from the Sentinel-1A satellite were used while examining the earthquake region.

\subsection{Vertical Deformations in Konya Karapınar District}

The lands of Karapınar, which is one of the most important agricultural areas and pastures in Turkey, have a calcareous structure up to $60 \%$. For this reason, sinkhole formation is observed as a natural and dynamic process due to karstification (Orhan et al., 2020). In addition, artesian wells drilled around Karapınar cause the depletion of groundwater. For this reason, a linear deformation is observed in the region.

Within the scope of the application, 15 SAR images were selected in the 1272-day period from 02.06.2016 to 26.11.2019. Since a linear 
deformation is expected while selecting the images, attention was paid to keep the time differences between consecutive images close to each other and the PS-InSAR method was used (average of 3 months).

\subsection{California Carr Fire}

The Carr Fire has taken its place in the literature as the 7 th largest fire in California. The fire, which started on 23.07.2018 and lasted for approximately 39 days, affected a land of 229,651 decares (Figure 7).

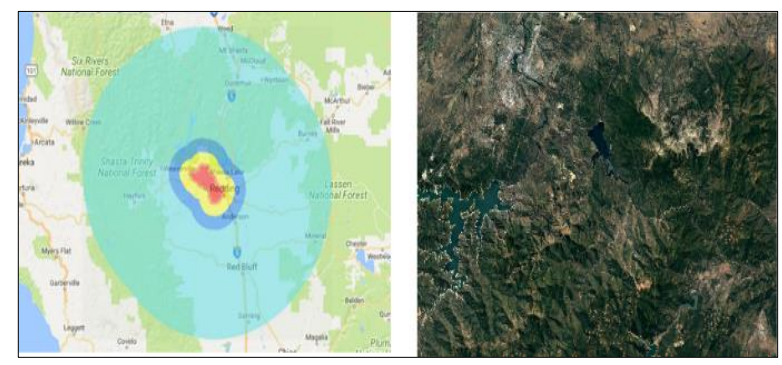

Figure 7. California Carr Fire impact zone

Since the determination of the starting point of the fire and the detection of the area of effect will be handled separately within the scope of the application, 3 SAR images were used. The fire caused chemical deterioration due to the burning of objects in the area where it originated. Objects exposed to chemical degradation lose both their chemical and physical properties. Therefore, the phase and amplitude values of the echoes reflected from the objects before the fire and the echoes reflected after the fire are different. The soil and rocks under the forest, which are formed as a result of this difference and the burning of forests, show different reflection properties from the forests. For this reason, change analysis methods were used in the California Carr Fire application.

\section{RESULTS AND DISCUSSION}

\subsection{Investigation of 2015 Chile Illapel Earthquake with DInSAR Method}

While creating interferograms for the examination of the Chile Illapel earthquake region, 8 separate interferograms were created from 3 SAR image pairs due to the structure of the SARPROZ program. Three of the interferograms obtained via route 150 were obtained from images with frame number 700, three of them with frame number 695 and the remaining two images with frame number 690. The interferograms obtained are given in Figure 8.

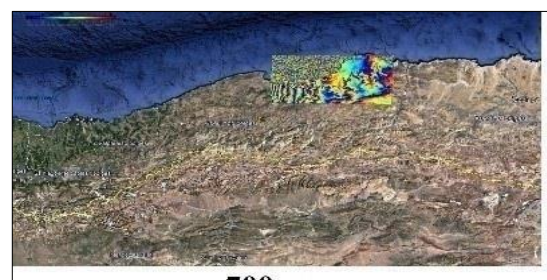

700-a

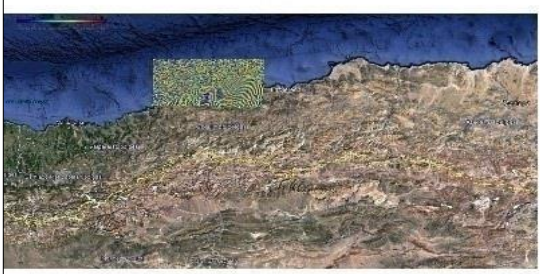

695-a

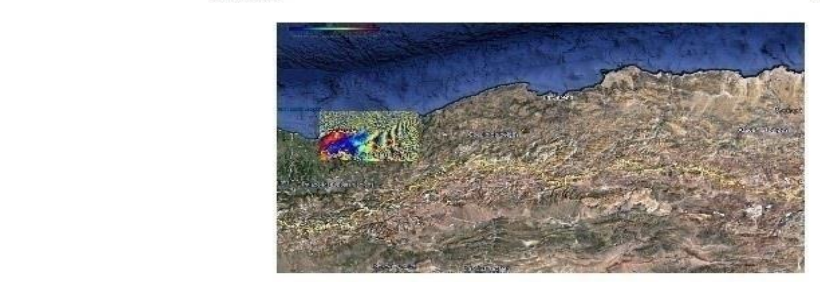

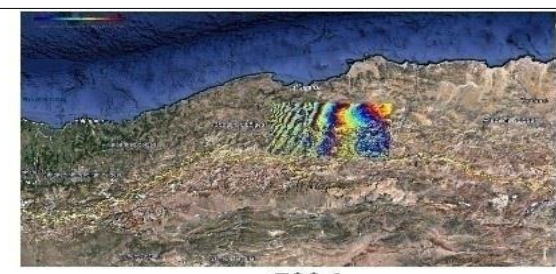

700-b

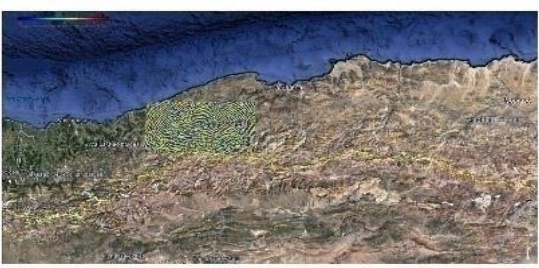

695-b

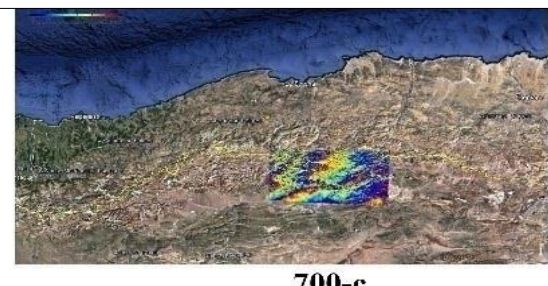

700-c

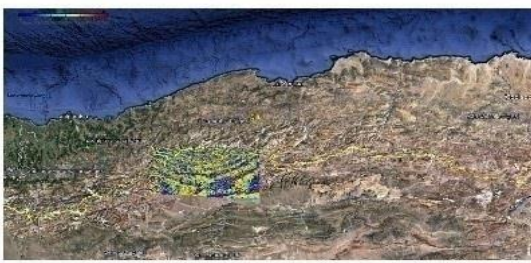

$695-c$
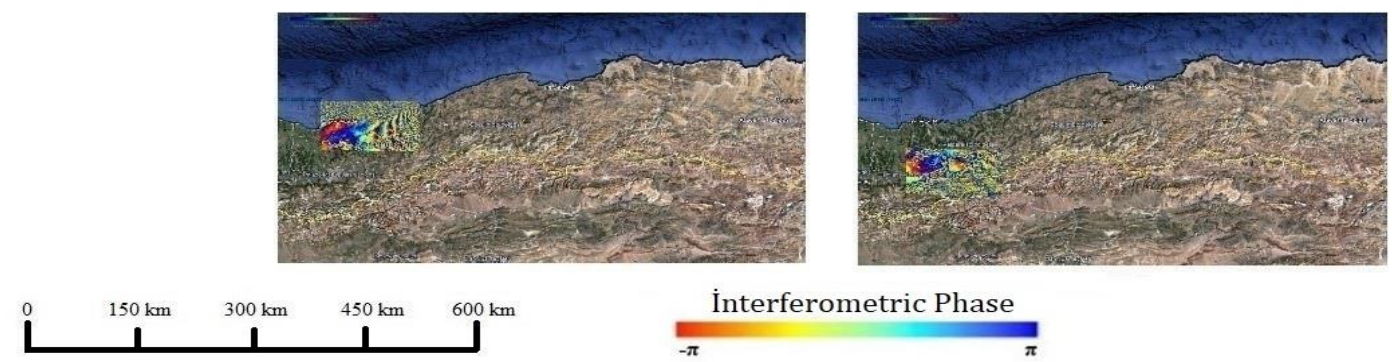

İnterferometric Phase $-\pi$

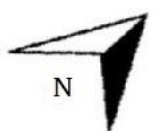

Figure 8. Interferograms generated from SAR images with track number 155

The created interferograms were combined with Google Earth and turned into a single interferogram. When the combined interferogram was examined, 54 fringe patterns with values ranging from $\pi$ to $-\pi$ were detected in the application area (Figure 9). 


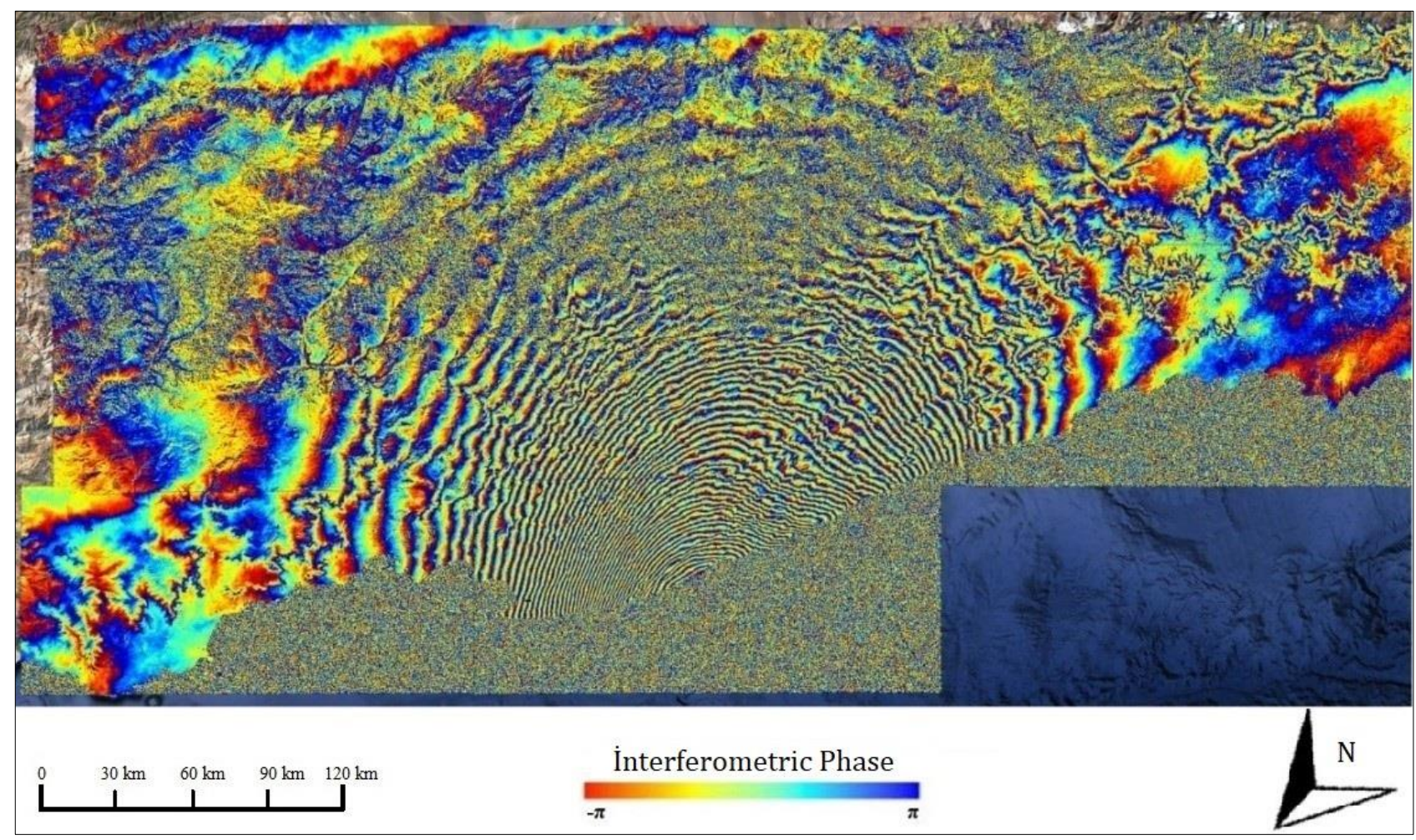

Figure 9. Combined interferogram used in the 2015 Chile Illapel earthquake application

In the DInSAR method, each pattern transition shows that there is a movement half the length of the electromagnetic wave used in image acquisition (in the LOS direction) (Curlander and McDonough, 1991; Çakır, 2003; Akoğlu, 2008; Şengün, 2008; Yllmaztürk, 2015). Since the wavelength of Sentinel$1 \mathrm{~A}$ satellite is $5.6 \mathrm{~cm}$, the deformation in the LOS direction in the 2015 Chile Illapel earthquake region was obtained as $\sim 151 \mathrm{~cm}$. When other studies conducted for the same region were examined, it was seen that the obtained displacement was around $150 \mathrm{~cm}$ (Solaro et al., 2016; Grandin et al., 2016; Klein et al., 2017).

\subsection{Investigation of Vertical Deformations in Konya Karapınar District by PS-InSAR Method}

In order to determine the vertical deformations in Konya Karapınar district, the application area was determined first. While determining the application area, it has been taken into consideration that the Karapinar surroundings are mostly composed of agricultural land. Therefore, the application area has been chosen to cover the center of the Karapınar district, which is a region with high reflectivity, suitable for the generation of a sufficient number of points for APS estimation and PS-InSAR method, and the surrounding rocky areas. After the images were selected, the image matching phase was started. While the images were matched, the image dated 04.06 .2018 was determined as the master image and the remaining images were determined as the slave image and the matching process was performed. Then, the APS estimation stage was passed to eliminate the atmospheric effect. In the APS estimation phase, the amplitude values such as soil and field are low, and in order to prevent the structures with disturbing factors from deteriorating the correlation, the lower limit value of agreement was determined as 0.7 based on the amplitude stability index and 719 APS points were produced (Figure 10).

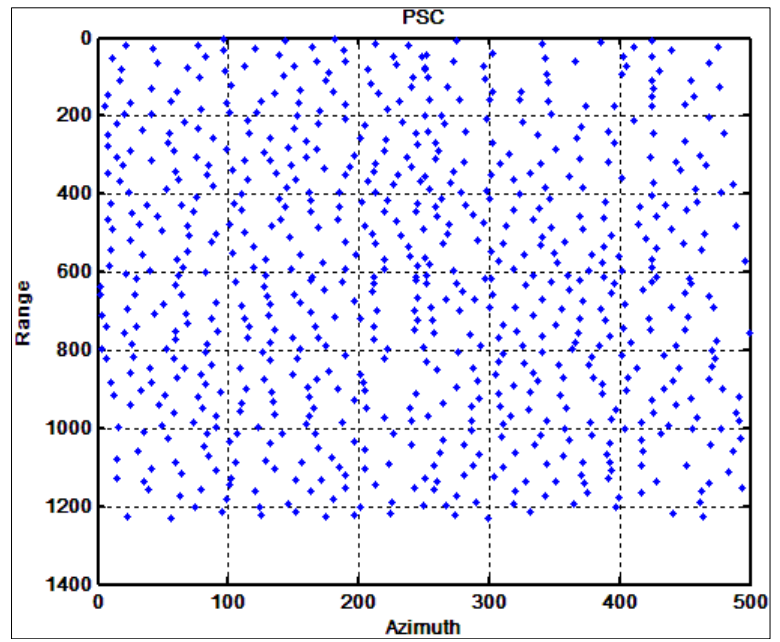

Figure 10. Points determined for APS estimation in Konya Karapınar application area

After generating the points for APS estimation and checking their consistency, the points were connected to each other using the Delaunay triangulation method and a network of 2136 triangles was obtained (Figure 11). 


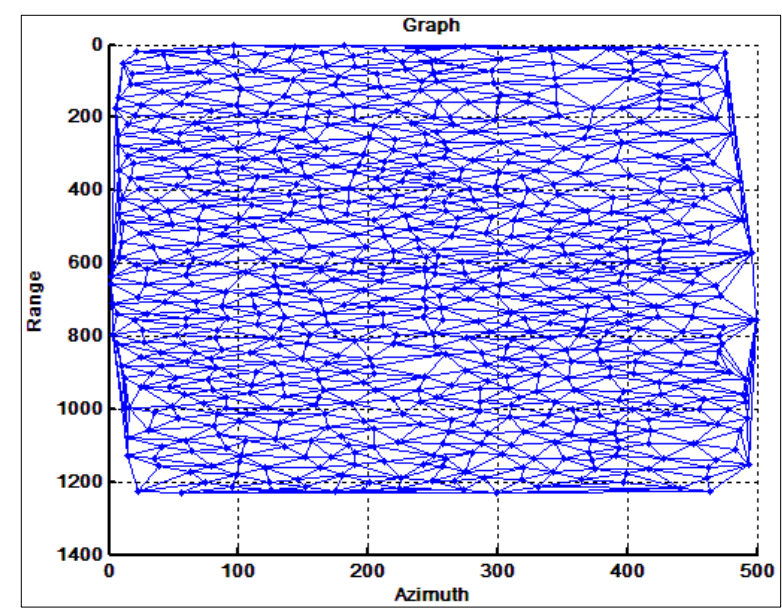

Figure 11. Delaunay triangle network formed with APS points determined in Konya Karapınar application area

Afterwards, atmospheric phase estimation was made and the atmospheric effect was eliminated. After the atmospheric effect was removed, the process of determining the PS points was started. While selecting the PS points, the lower limit of the agreement value was selected as 0.65 based on the amplitude stability index and 9478 points were determined (Figure 12).

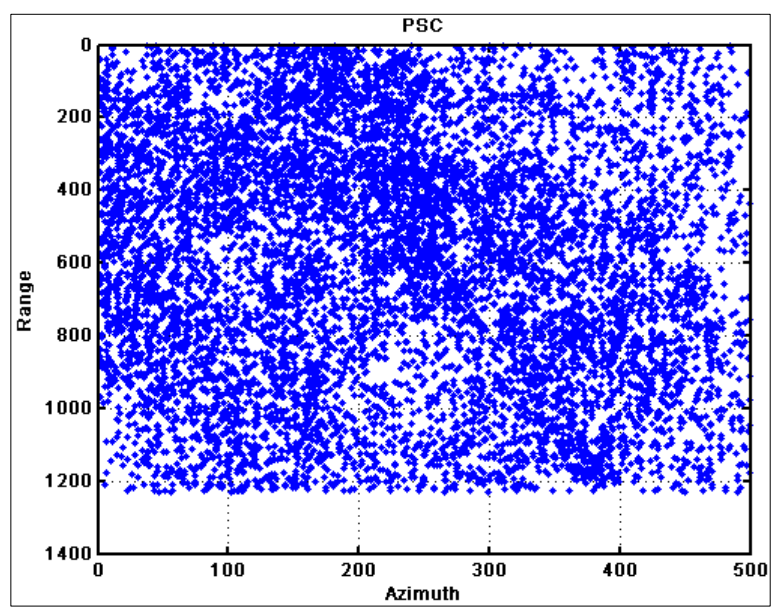

Figure 12. PS points determined in Konya Karapınar application area

The determined points were filtered by choosing a temporal consistency value of 0.8 and reduced to 5713 points. Filtered points were opened on Google Earth using time series of the 5713 points. When the annual average movements of the obtained PS points in the LOS direction are examined, it has been determined that the movements of the points in the district center vary between $-5 \mathrm{~mm}$ and $-10 \mathrm{~mm}$, the movements of the points in the region between the district center and the agricultural lands vary between $-10 \mathrm{~mm}$ and -20 $\mathrm{mm}$, and the movements of the points near the agricultural areas vary between $-20 \mathrm{~mm}$ and -50 mm (Figure 13).

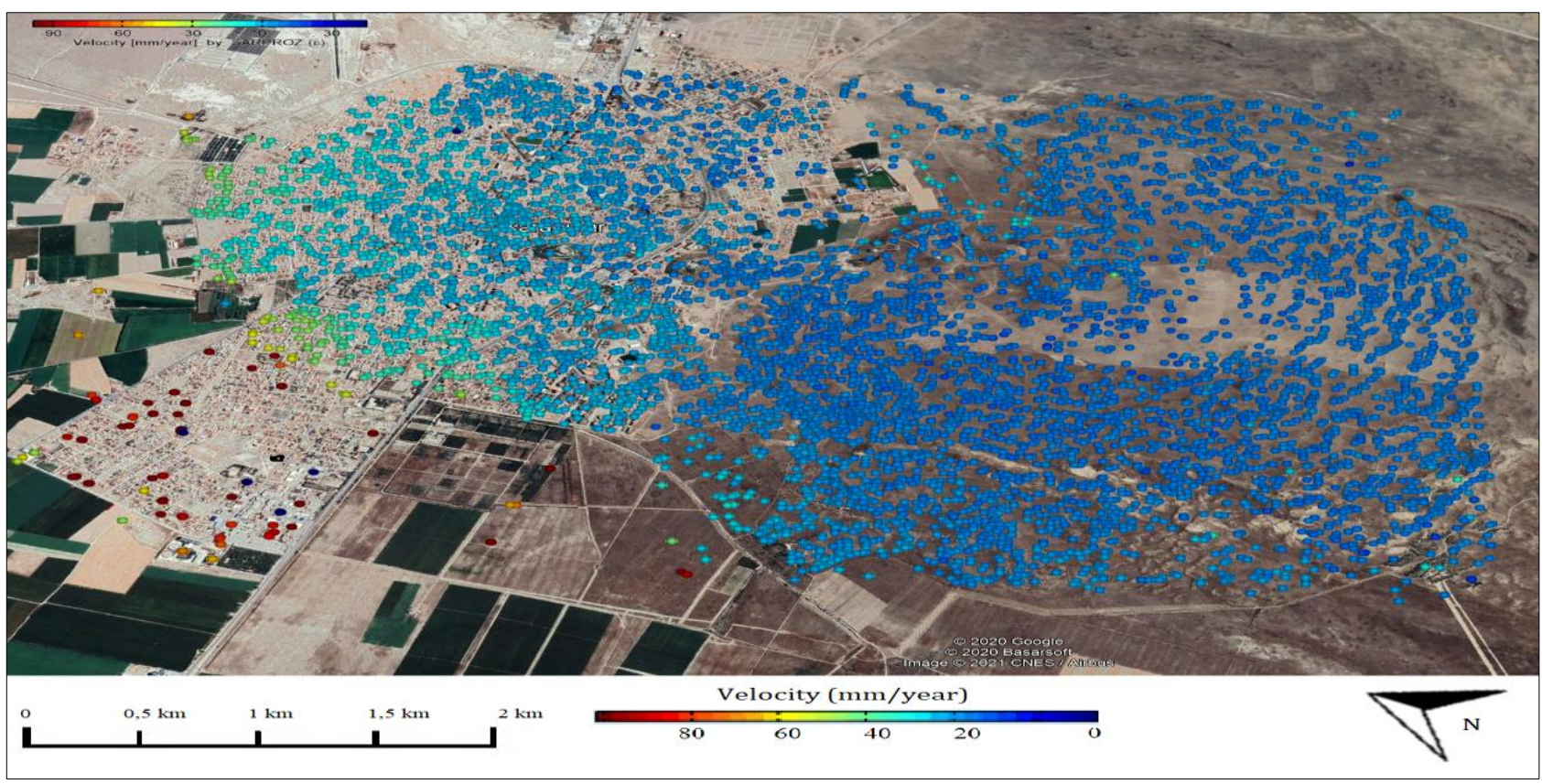

Figure 13. Distribution of PS points with a temporal correlation of 0.7 and above determined in Konya Karapınar application area

However, the deformation in the application area occurs vertically in terms of the reasons for its occurrence. For this reason, deformation values in the LOS direction were converted to vertical deformation values (Table 1) 
Table 1. The average values of the annual average movements in the LOS direction and their vertical equivalents of the PS points used in Konya Karapınar application, according to the distribution of the points

\begin{tabular}{ccc} 
Area & LOS (mm) & Vertical (mm) \\
\hline Center of district & {$[-5,-10]$} & {$[-6,4,-12,7]$} \\
$\begin{array}{c}\text { The area between the center of } \\
\text { district and agricultural lands. } \\
\text { Areas close to agricultural fields }\end{array}$ & {$[-10,-20]$} & {$[-12,7,-25,5]$} \\
& {$[-20,-50]$} & {$[-25,5,-63,7]$}
\end{tabular}

\subsection{Investigation of California Carr Fire with Change Analysis}

Since the determination of the starting point of the fire and the detection of the area of effect will be handled separately within the scope of the application, 3 SAR images were used. After the images were selected, the matching phase of the images was started. While matching the images, the image dated 12.07.2018 to be used in both applications was determined as the master image, and the images dated 24.07.2018 and 10.09.2018 were determined as the slave image. After the images were matched, the application phase was started. In both applications, the change detection was made with the method in which only amplitude values were used and the general coherent map using phase and amplitude values.

In the images created with the SARPROZ program with the first method in which only the amplitude values of the images are used, the places where the amplitude values of the pixels in the master image are less than the amplitude values of the pixels in the slave image are expressed with yellow pixels, and the places where they are more are expressed with blue pixels. In this way, the starting point of the fire and the effect area of the fire were determined by determining the increasing amplitude values (blue colored pixels) due to the emergence of the rock and soil under the forest lands destroyed by the fire. In the second method, in which both amplitude and phase values are used, the regions under the effect of shadowing or the places where the harmony decreases in the general coherent maps created by the SARPROZ program are expressed with black toned pixels. In this way, the starting point of the fire and the effect area of the fire were determined by determining the places where the consistency fell. In the study, in which the starting point of the fire was determined, the change analysis using the amplitude values was performed, the lower limit value of the change was determined as 0.14 , and the differences below this value were filtered by assuming noise. The filter window size was determined as 25 in order to reduce the estimation uncertainty and increase the consistency without reducing the spatial resolution too much, since the application area consists of dense forest land. After determining the noise threshold and filter window size, an image was created by taking the difference of the amplitude values of the corresponding pixels of the SAR images dated 12.07.2018 and 24.07.2018. After the image was created, the blue pixels were determined and the area where the fire started was determined. In the second method, in which phase and amplitude values are used, a general coherent map was created using images dated 12.07.2018 and 24.07.2018. In the map created, the areas where the adaption decreased were determined by black toned pixels and the area where the fire started was determined. Then, the two images were combined on Google Earth to better observe the starting point of the fire (Figure 14). 


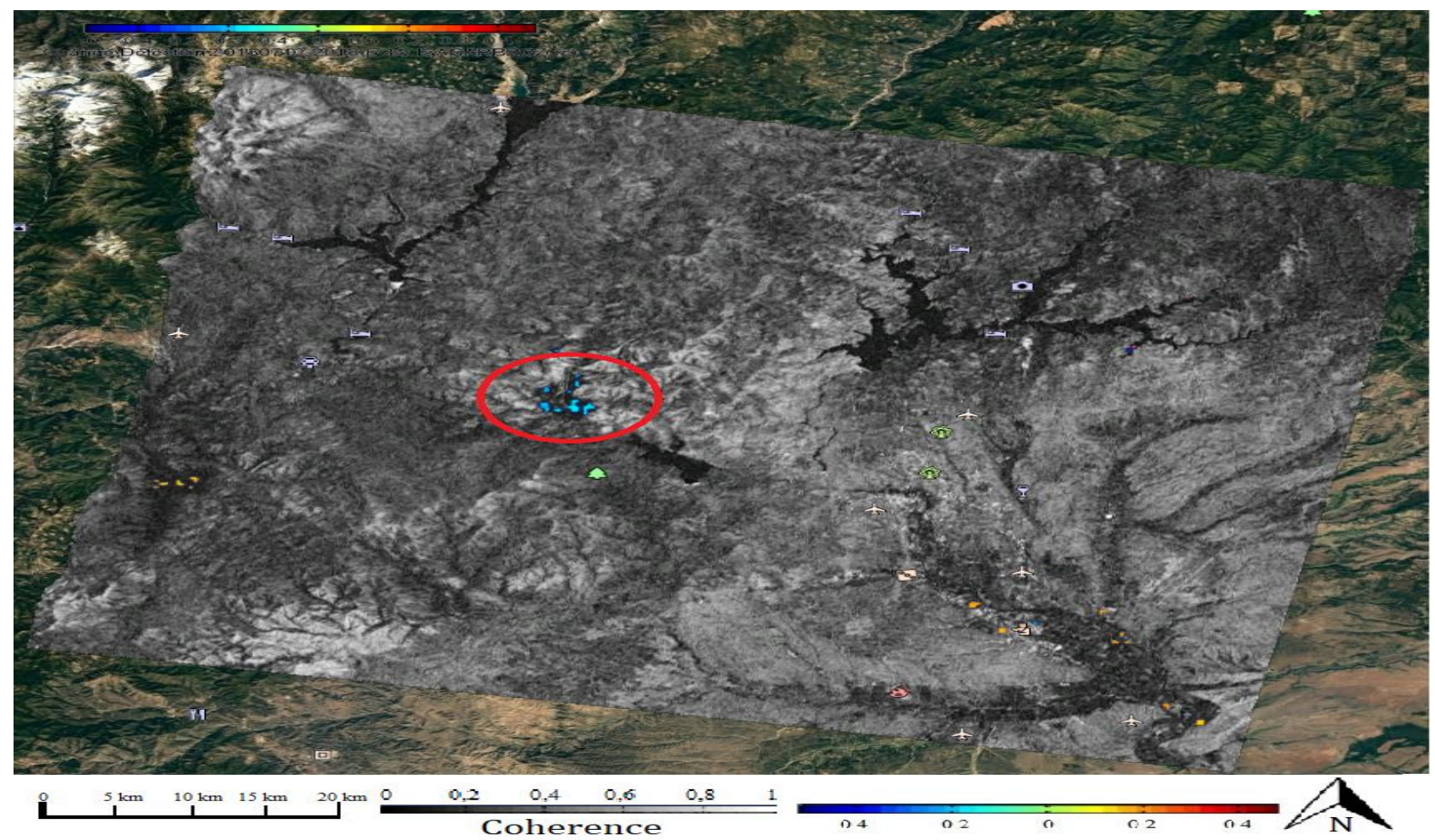

Figure 14. The starting point of the California Carr Fire, which was determined as a result of combining the images from the two methods

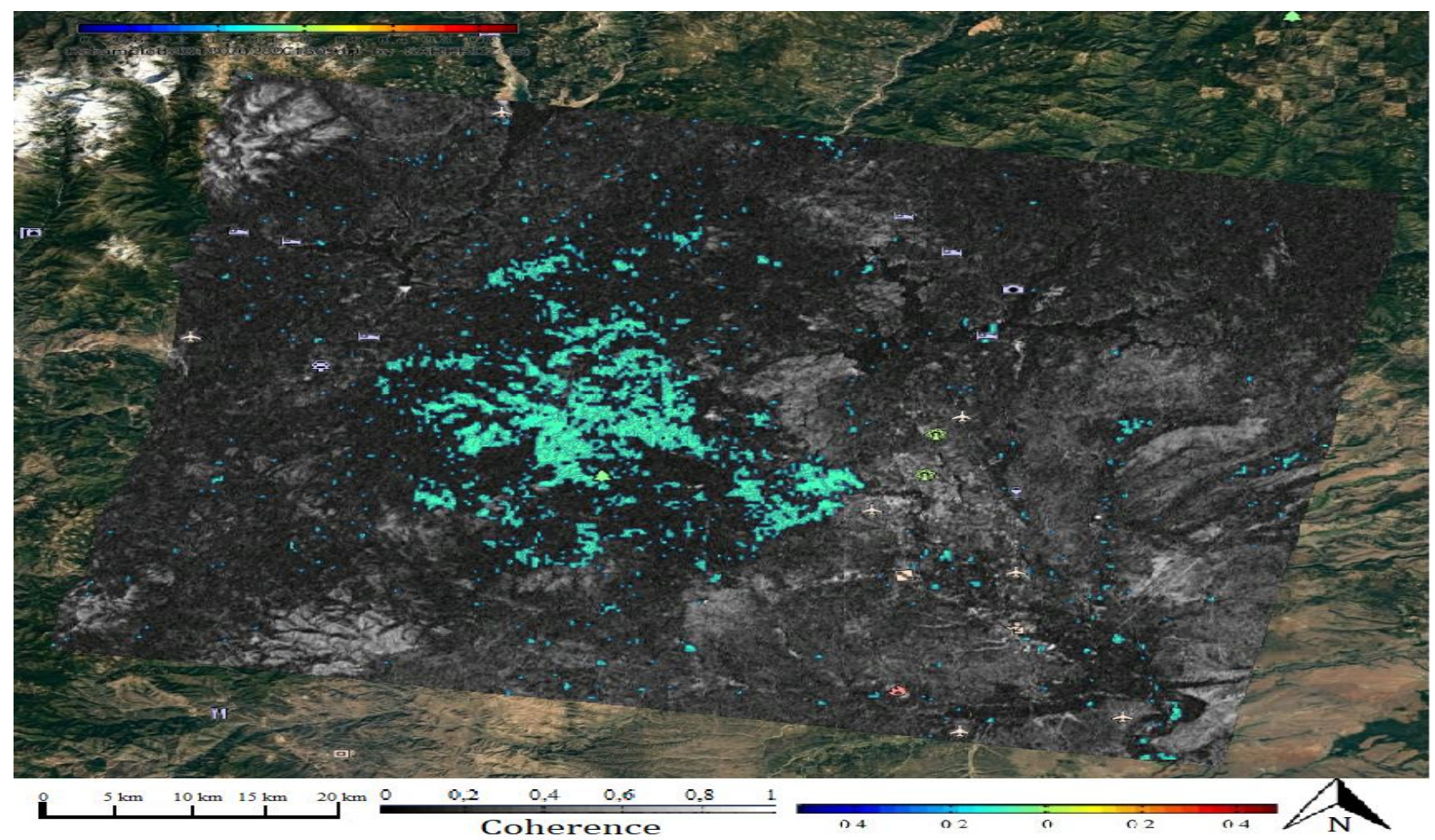

Figure 15. The effect area of the California Carr Fire which is determined as a result of combining the images from the two methods

In the analysis in which the effect area of the California Carr Fire was determined, firstly, the change analysis method with the amplitude values of SAR images was used. As a result of the applications made with different values, it was seen that the best results were obtained when the lower limit value was determined as 0.142 . The filter window size remained the same as the value in the application where the starting point of the fire was determined. After determining the noise threshold 
and filter window size, an image was created by taking the difference of the amplitude values of the corresponding pixels using the SAR images dated 12.07.2018 and 10.09.2018. The area where the fire started was determined by determining the blue pixels in the image created after the image was created. In the second method, in which phase and amplitude values are used, a general coherent map was created using images dated 12.07.2018 and 10.09.2018. Areas of influence of the fire were determined by determining the black toned pixels where the coherent decreased in the map created. Then, the two images were combined on Google Earth in order to better observe the impact area of the fire (Figure 15).

\section{CONCLUSION}

The research examining the 2015 Chile Illapel earthquake reveals the ability of the InSAR method to map large areas such as 93000 square kilometers, which is the entire application area of the 2015 Chile Illapel earthquake. The research examining the Vertical Deformations in Konya Karapınar shows that linear deformations can be determined from the measurements made with the PS-InSAR method and the average velocities of the deformations can be calculated. In addition, it has been observed that the LOS directional deformations obtained as output can be converted to real deformation values with a simple transformation if the deformation is unidirectional. In this context, unidirectional deformations such as collapse, abrasion, and sinkhole formations can be determined by the PS-InSAR method. Research examining the California Carr Fire shows that fire detection studies with Change detection are successful and can be used in the detection of fire areas.

When the whole research is considered completely, it is seen that the InSAR method can be used in different disaster researches. In addition, Sentinel-1 satellite images, which are free of charge, with a wavelength of $5.6 \mathrm{~cm}$ (C-band) and a period of 12 days facilitate research on disasters such as earthquakes, tsunamis, fires, and explosions in any region. Since the satellite system can take images in a fixed period and has been active since 2014, it enables the investigation of disasters such as volcanic movements and landslides with time series.

\section{ACKNOWLEDGEMENT}

This article was produced from Bekir GÜNDOĞDU's master thesis. The Scientific and Technological Research Council of Turkey (TÜBITTAK) provided financial support to Bekir GÜNDOĞDU's graduate education within the scope of the 2210/A General Domestic Post Graduate Scholarship Program. The authors thank Prof. Dr. Daniele PERRISIN for giving permision free access to the SARPROZ software.

\section{REFERENCES}

Akabalı, A. (2002). Stereo yapay açıklıklı radar görüntülerinden otomatik sayısal yükseklik modeli üretilmesi ve doğruluğunun araştırılması (MSc thesis) Yildiz Technical University, Istanbul, Turkey.

Akoğlu, A. M. (2008). Analysis and modelling of the earthquake surface deformation with SAR interferometry: Case studies from Turkey and the world (PhD thesis) Istanbul Technical University, Istanbul, Turkey.

Altun, F. (2018). Afetlerin ekonomik ve sosyal etkileri: Türkiye örneği üzerinden bir değerlendirme. Sosyal Çalışma Dergisi, 2(1), 115.

Balık Şanlı, F. (2004). Elektro-optik ve SAR uydu görüntüleri ile arazi bitki örtüsünün belirlenmesi (PhD thesis) Yildiz Technical University, Istanbul, Turkey.

Bamler, R., \& Hartl, P. (1998). Synthetic aperture radar interferometry. Inverse Problems, 14(4), $1-54$.

Carnec, C., Massonnet, D., \& King, C. (1996). Two examples of the use of SAR interferometry on displacement fields of small spatial extent. Geophysical Research Letters, 23(24), 35793582.

Curlander, J.C., \& McDonough, R.N. (1991). Synthetic aperture radar systems and signal processing. John Wiley \& Sons, Inc., Press, New York, USA.

Çakır, Z. (2003). Analysis of the crustal deformation caused by the 1999 İzmit and Düzce Earthquakes using synthetic aperture radar interferometry (PhD thesis). Istanbul Technical University, Istanbul, Turkey.

Elachi, C. (1988). Spaceborne radar remote sensing: Applications and techniques. IEEE Press, New York, ABD.

Ferretti, A., Prati, C., \& Rocca, F. (1999). Process for radar measurements of the movement of city areas and landsliding zones. EPO Pattent NO: EP1183551B, European Patent Office.

Ferretti, A., Prati, C., \& Rocca, F. (2000). Nonlinear subsidence rate estimation using permanent scatterers in differential SAR interferometry. IEEE TGRS, 38, 5, 2202-2212.

Fielding, E.J., Blom, R.G. \& Goldstein, R.M. (1998). Rapid subsidence over oil fields measured by SAR interferometry. Geophysical Research Letters, 25(17), 3215-3218. 
Fujiwara, S., Rosen, P.A., Tobita, M., \& Murakami, M. (1998). Crustal deformation measurements using repeat-pass JERS 1 synthetic aperture radar interferometry near the Izu Peninsula, Japan. Journal of Geophysical Research: Solid Earth, 103(B2), 2411-2426.

Gabriel, A.K., Goldstein, R.M., \& Zebker, H. (1989). Mapping small elevation changes over large areas: Differential radar interferometry. Journal of Geophysical Research, 94,9183-9191.

Goldstein, R.M., \& Zebker, H.A. (1987). Interferometric radar measurement of ocean surface currents. Nature, 328(6132), 707-709.

Goldstein, R.M., Engelhardt, H., Kamb, B., \& Frolich, R. M. (1993). Satellite radar interferometry for monitoring ice sheet motion: Application to an Antarctic ice stream. Science, 262(5139), 15251530.

Graham, L.C. (1974). Synthetic interferometer radar for topographic mapping. Proceedings of the IEEE, 62(6), 763.

Grandin, R., Klein, E., Métois, M., \& Vigny, C. (2016). Three-dimensional displacement field of the 2015 Mw8.3 Illapel earthquake (Chile) from across-and along-track Sentinel-1 TOPS interferometry. Geophys. Res. Lett., 43(6), 25522561.

Hanssen, R.F. (2001). Radar interferometry data interpretation and error analysis. Kluwer Academic Publishers, Dordrecht, Hollanda.

Haynes, M., Capes, R., Lawrences, G., Smith, A., Shilston, D., \& Nicholls, G. (1997). Majorurban subsidence mapped by differential SAR interferometry, The 3rd ERS Symposium (ESA). Florence, Italy, 18-21.

Massonnet, D., Briole, P., \& Arnaud, A. (1995). Deflation of Mount Etna monitored by spaceborne radar interferometry. Nature, 375(6532), 567-570.

Massonnet, D., \& Feigl, K. L. (1995). Discrimination of geophysical phenomena in satellite radar interferograms. Geophysical Research Letters, 221(2), 1537-1540.

Massonnet, D., Rossi, M., Carmona, C., Adragna, F., Peltzer, G., Feigl, K., \& Rabaute, T. (1993). The displacement field of the Landers earthquake mapped by radar interferometry. Nature, 364(6433), 138-142.

Meyer, B., Armijo, R., Massonnet, D., De Chabalier, J. B., Delacourt, C., Ruegg, J.C., \& Papanastassiou, D. (1996). The 1995 Grevena (northern Greece) earthquake: Fault model constrained with tectonic observations and SAR interferometry. Geophysical Research Letters, 23(19), 26772680.

Murakami, M., Tobita, M., Fujiwara, S., Saito, T., \& Masaharu, H. (1996). Coseismic crustal deformations of 1994 Northridge, California, earthquake detected by interferometric JERS 1 synthetic aperture radar. Journal of Geophysical Research: Solid Earth, 101(B4), 8605-8614.

Orhan, O., Kırtıloğlu, O.S., \& Yakar, M. (2020). Konya kapalı havzası obruk envanter bilgi sisteminin oluşturulması. Geomatik, 5(2), 81-90.

Ozawa, S., Murakami, M., Fujiwara, S., \& Tobita, M. (1997). Synthetic aperture radar interferogram of the 1995 Kobe Earthquake and its geodetic inversion. Geophysical Research Letters, 24(18), 2327-2330.

Peltzer, G., Hudnut, K. W., \& Feigl, K. L. (1994). Analysis of coseismic surface displacement gradients using radar interferometry: New insights into the Landers earthquake. Journal of Geophysical Research: Solid Earth, 99(B11), 21971-21981.

Peltzer, G., \& Rosen, P. (1995). Surface displacement of the 17 May 1993 Eureka Valley, California, earthquake observed by SAR interferometry. Science, 268(5215), 1333-1336.

Price, E.J., \& Sandwell, D.T. (1998). Small-scale deformations associated with the 1992 Landers, California, earthquake mapped by synthetic aperture radar interferometry phase gradients. Journal of Geophysical Research: Solid Earth, 103(B11), 27001-27016.

Ristau, J.P. (1999). Applications of synthetic aperture radar interferometry in the study of the nahanni earthquake region (MSc thesis) Manitoba University, Manitoba, Canada.

Rocca, F., Prati, C., \& Ferretti, A. (2010). Space-borne SARs: impact of wavelengths and scan modes on ground motion studies. Annals of GIS, 16(2), 69-79.

Rogers, A.E.E., \& Ingalls, R.P. (1969). Venus: Mapping the surface reflectivity by radar interferometry. Science, 165(3895), 797-799.

Rosen, P.A., Hensley, S., Zebker, H. A., Webb, F.H., \& Fielding, E.J. (1996). Surface deformation and coherence measurements of Kilauea Volcano, Hawaii, from SIR-C radar interferometry. Journal of Geophysical Research, Planets, 101(E10), 23109-23125. 
Salora, G., De Novellis, V., Castaldo, R., De Luca, C., Lanari, R., Manunta, M., \& Casu, F. (2016). Coseismic fault model of Mw 8.32015 Illapel earthquake (Chile) retrieved from multi-orbit Sentinel1-A DInSAR measurements. Remote Sens., 8(4), 323.

Şengün, Y.S. (2008). GPS ve InSAR ölçülerini birlikte kullanarak İzmit Depreminde oluşan deformasyonun modellenmesi (PhD thesis) Istanbul Technical University, Istanbul, Turkey.

Tomás, R., \& Li, Z. (2017). Earth observations for geohazards: present and future vhallenges. Remote Sensing, 9(3), 194.

Vadon, H., \& Sigmundsson, F. (1997). Crustal deformation from 1992 to 1995 at the MidAtlantic ridge, Southwest Iceland, mapped by satellite radar interferometry. Science, 275(5297), 193-197.
Wang, Z., Balz, T., Zhang, L., Perissin, D., \& Liao, M. (2009). Using TSX/TDX pursuit monostatic SAR stacks for PS-InSAR analysis in urban areas. Remote Senssing, 11, 1, 26.

Yılmaztürk, S. (2015). SBAS-InSAR yöntemiyle düșey yönlü yüzey deformasyonlarının belirlenmesi: Bursa-Orhaneli linyit madeni örneği (MSc thesis) Istanbul Technical University, Istanbul, Turkey.

Url-1: https://www.sarproz.com, (last accessed 2 April 2018)

Url-2: https://www.radartutorial.eu/01.basics /pic/radarprinzip.print, (last accessed 4 November 2019) 